\title{
Study on Harmonic Resonance and Grid-Connected Control Technology of Doubly-Fed Wind Turbines
}

\author{
Jin XU, Haiyun CHEN, Wanming ZHAO, Qian LI
}

\begin{abstract}
The development of clean energy has been paid more and more attention. The installed capacity of wind turbine is increasing, but wind turbine is prone to be affected by grid deformation as the stator of wind turbine is connected directly with power grid, and the power grid of wind farm is at the end of the whole grid, and its connection is weak. In order to reduce the influence of grid distortion on wind turbine, harmonic current suppression test was carried out on the doubly-fed wind power integration platform built based on the mathematical model of the wind power system using stator current harmonic control, and it was compared with the traditional current control method. No matter the rotational speed of the motor was subsynchronous or supersynchronous, the proposed method always had better performance in controlling harmonic current. Six times of pulse frequency of the electromagnetic torque could be effectively suppressed when the control strategy was switched from the traditional control method to the method which was put forward by this study under supersynchronous rotational speed. In conclusion, the method proposed in this paper can effectively suppress the influence of the harmonic voltage generated by the grid distortion on current in grid and improve the operation stability of doubly-fed wind motor.
\end{abstract}

Keywords: doubly-fed motor; grid-connected control; harmonic resonance; wind power generation

\section{INTRODUCTION}

Energy plays an important role in modern economic development. However, coal is still the most important non-renewable resource in China, and renewable energy only occupies a small part, which is extremely unfavorable to sustainable development [1]. With the emergence of the concept of energy saving and emission reduction, development of various renewable energy has been proposed, such as the development and utilization of wind resources. As a widely distributed and renewable clean energy, wind power generation has made tremendous progress with the support of the government, and the cumulative installed capacity has increased year by year [2]. However, most wind farms are built in remote and open areas, i.e., at the end of the overall structure of the grid. Because of the weak network structure, it is difficult to withstand the impact of excessive changes when connected to the grid, and fluctuations may affect the safety of the whole grid [3].

To solve those problems, grid-connected control is more important than improvement of hardware performance of electric motor. Yu et al. [4] put forward resonant sliding mode control in the static reference coordinate of stator which realized the control target of sinusoidal output currents or stable stator output active/reactive power and improved the quality of doubly fed induction generator output power under unbalance and harmonics grid voltage conditions. Ratna et al. [5] analyzed sub-synchronous resonance due to series compensated transmission line which is connected to doubly fed induction generator (DFIG) and mitigating the subsynchronous resonance by improving the rotor side converter (RSC) and grid side converter (GSC) simple and easy to implement control technique of doubly fed induction generator. The testing of modelling of the system on Matlab suggested that the control technique was effective. Ji et al. [6] put forward a voltage control strategy for stand-alone operation brushless double-fed induction generators in variable speed constant frequency wind power system. The proposed direct flux control strategy employs a nonlinear reduced-order generalized integratorbased resonant sliding-mode control approach to directly calculate and regulate the output value of converter which the control winding stator requires so as to eliminate its instantaneous errors, without involving any synchronous rotating coordinate transformations. Moreover the feasibility and effectiveness of the scheme was verified through experiments, and favourable steady and transient performance was achieved. In this study, harmonic current suppression experiment was carried out using stator current harmonic control on the experiment platform of doubly-fed wind power grid which was built according to the mathematical model of wind power system. It was compared with the traditional current control strategy to suggest the advantages of the proposed method.

\section{DOUBLY-FED WIND TURBINES}

As shown in Fig. 1, a wind turbine is composed of wind wheel, gear case, doubly-fed induction generator, Pulse-Width Modulation (PWM) rectification inverter and control device [7]. Doubly-fed induction generator is similar to asynchronous induction motor, the stator is the three-phase distributed winding, and the rotor is also the three-phase distributed winding, which is different from general alternating-current generator. When the doubly-fed wind turbine is working, the wind wheel is driven to rotate by wind, then the rotor of the doubly-fed induction generator is driven through the speed change of the gear case, the alternating current generates under the effect of the coil which is wrapped around the stator and adjusted through rectification inverter, and finally the current is connected to the public supply system. According to the principle that the magnetic field generated by the rotor and stator winding current of the asynchronous machine is relative static, the relationship between rotational speed and winding current [8] is:

$F_{1}=\frac{a r}{60} \pm F_{2}$

where $F_{1}$ refers to the winding current frequency of stator, $F_{2}$ refers to the winding current frequency of rotor, $r$ refers to the rotational speed of motor, and $a$ refers to pair of poles of motor. The stator current frequency and connected 
power frequency can be consistent to realize gridconnected control of wind turbines as long as the current frequency of the rotor is adjusted.

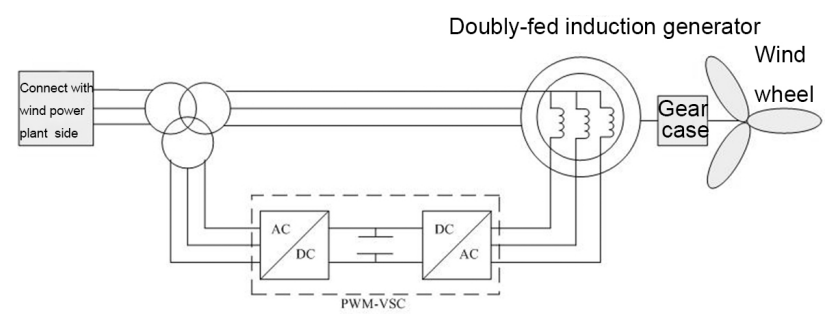

Figure 1 The model structure of doubly-fed wind turbines

\section{HARMONIC RESONANCE GRID-CONNECTED CONTROL TECHNIQUE}

In doubly-fed wind turbine system, harmonics with limited amplitude will be generated during operation as the total power is large, the reactance of motor and grid-side converter is small, and the switching frequency of converter is small [9]. Harmonic waves with limited amplitude will not produce large influence on electric field when wind turbine does off-grid operation, but will produce harmonic resonance if grid deforms after grid connection; as a result, the current which is transmitted from grid to wind turbine will include harmonics with a large amplitude, which will finally affect the operation environment of the whole power system.

To inhibit the harmonic wave on the operation environment of grid, stator current harmonics was inhibited using resonant controller in wind power converter. The control structure [10] is shown in Fig. 2.

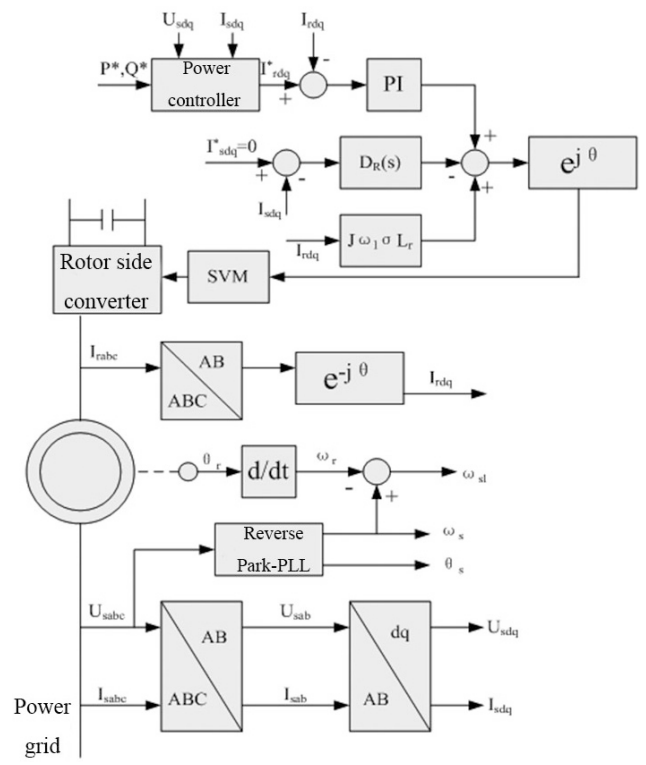

Figure 2 The stator current harmonic control strategy based on resonant controller

In Fig. 2, the structure in the dashed box is a resonant controller, which is different from the traditional control structure. The transfer function of resonant controller [11] is:

$$
D_{R}(s)=\frac{2 H_{r} \omega_{c} s}{s^{2}+2 \omega_{c} s+\omega_{0}^{2}},
$$

where $H_{r}$ refers to controller's gain for harmonic resonance frequency, $\omega_{0}$ refers to the resonant frequency of harmonic, and $\omega_{c}$ refers to the open loop cut-off frequency when $H_{r}=$ 1. The gain attenuates fast when resonant controller is at a non-resonant frequency, suggesting an obvious frequencyselection characteristic.

It can be seen from Fig. 2 that the voltage command of rotor converter was in a correlation with output of PI controller, output of resonant controller and current decoupling term of rotor, and its expression [12] is

$U_{r d q}^{*}=U_{r d q}^{P I} \quad U_{r d q}^{R}+U_{r d q}^{C}$

where $U_{r d q}^{*}$ stands for the voltage command of rotor converter, $U_{r d q}^{P I}$ stands for output of PI controller, $U_{r d q}^{R}$ stands for output of resonant controller, and $U_{r d q}^{C}$ stands for current decoupling term of rotor; when the system is in a steady state, $U_{r d q}^{P I}$ is direct current variable and $U_{r d q}^{R}$ is the 6 th alternating current variable.

To inhibit the $5^{\text {th }}$ and $7^{\text {th }}$ harmonic current as far as possible, the execution frequency of resonant controller [13] in $d q$ synchronous rotating coordinate system $\omega_{0}$ should be equal to $6 \omega_{s}$.
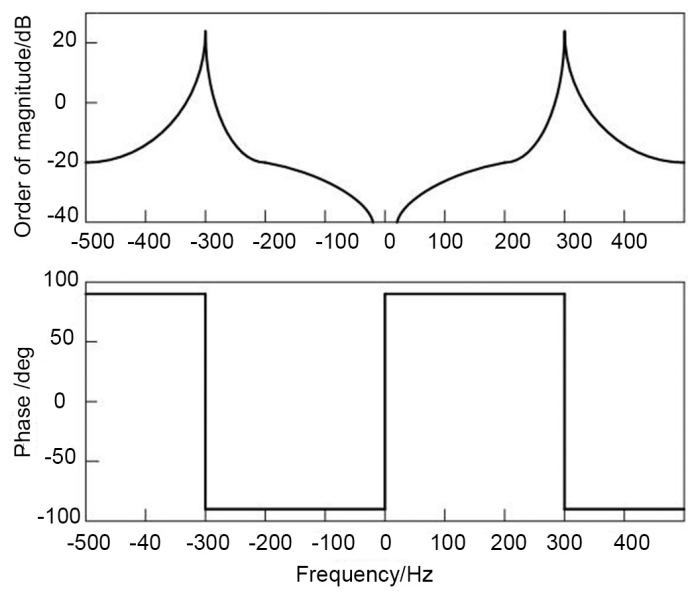

Figure 3 The frequency characteristics of resonant controller

The Bode diagram of resonant controller when $H_{r}=20$, $\omega_{c}=5 \mathrm{rad} / \mathrm{s}$ and $\omega_{0}=1785 \mathrm{rad} / \mathrm{s}$ [14] is shown in Fig. 3. It could be seen from Fig. 3 that the control gain of resonant controller was the largest when the frequency of resonant controller was at $+300 \mathrm{~Hz}$ and $-300 \mathrm{~Hz}$, and the positive sequence $7^{\text {th }}$ and $5^{\text {th }}$ harmonic frequency in the $d q$ synchronous rotating coordinate system exactly corresponded to the two frequencies with the largest control gain, which indicated that harmonic controller had favourable frequency selection performance and had a good control effect for harmonics with integral multiple of frequency.

\section{EXPERIMENTAL ANALYSIS \\ 4.1 Experimental Structure}

The schematic diagram of circuit structure in this experiment [15] is shown in Fig. 4. The whole experimental system is composed of driver frequency 
converter, driver motor, doubly-fed motor, doubly-fed converter, control circuit and computer used for monitoring. Driver motor and driver frequency converter are used for simulating the wind turbine in wind power generation, i.e., the rotational speed of normally operated doubly-fed motor. Rotor side converter and grid side converter constitute doubly-fed converter. Two converters and their control circuits are independent from each other, only connected via direct current bus capacitance. Both control circuits include AD signal sampling device, driver circuit, Digital Signal Processor (DSP) and harmonic control algorithm. DSP coordinate with each other via Controller Area Network (CAN) communication and include respective resonant control algorithm. DSP of rotor-side converter interacts with computer to convey control command and operation state.

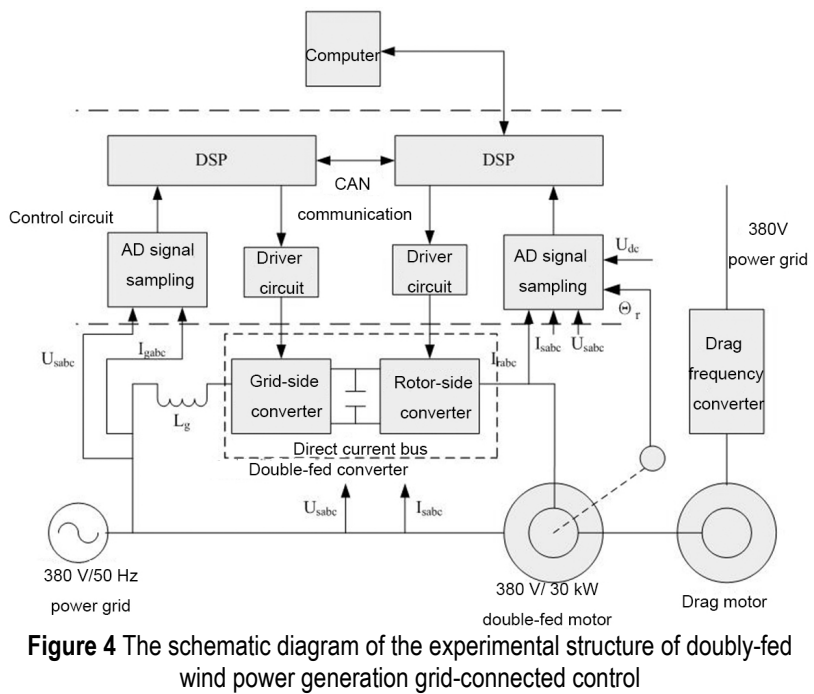

\subsection{Experimental Parameters}

Relevant parameters of the experimental structure are shown in Tab. 1. The rated capacity of the doubly-fed generator was $30 \mathrm{~kW}$, the rated working frequency was 50 $\mathrm{Hz}$, the maximum working voltage was $380 \mathrm{~V}$, and the synchronous speed was $1600 \mathrm{r} / \mathrm{min}$. The rated capacity of the converter was $10 \mathrm{~kW}$, the switching frequency was 1.5 $\mathrm{kHz}$, and the sampling frequency was $3.5 \mathrm{kHz}$. The direct current bus capacitance was $1500 \mu \mathrm{F}$. The induction of the grid side converter alternating current was $15 \mathrm{mH}$, resonant controller $K_{r}$ was 25 . The open-loop cut-off frequency $\omega_{c}$ was $10 \mathrm{r} / \mathrm{s}$.

Table 1 The relevant parameters of the experimental structure

\begin{tabular}{|l|l|}
\hline \multicolumn{1}{|c|}{ Item } & \multicolumn{1}{c|}{ Parameter } \\
\hline Doubly-fed motor & $\begin{array}{l}\text { Rated capacity: } 30 \mathrm{~kW} \text {; rated } \\
\text { frequency: } 50 \mathrm{~Hz} \text {; synchronous } \\
\text { speed: } 1600 \mathrm{r} / \mathrm{min}\end{array}$ \\
\hline Converter & $\begin{array}{l}\text { Rated capacity: } 10 \mathrm{~kW} ; \\
\text { switching frequency: } 1.5 \mathrm{kHz} ; \\
\text { sampling frequency: } 3.5 \mathrm{kHz}\end{array}$ \\
\hline Direct current bus capacitance & $1500 \mu \mathrm{F}$ capacitance \\
\hline $\begin{array}{l}\text { Grid side converter alternating } \\
\text { current inductance }\end{array}$ & $15 \mathrm{mH}$ induction \\
\hline PI controller of rotor side converter & $K_{p}=0.35, K_{i}=35$ \\
\hline Harmonic controller & $K_{r}=25, \omega_{c}=10 \mathrm{r} / \mathrm{s}$ \\
\hline
\end{tabular}

The calculation formulas of $K_{p}, K_{i}$ of PI controller of rotor side converter [16] are:

$$
\left\{\begin{array}{l}
\left|\left(K_{p}+\frac{K_{i}}{2 \pi f_{c r}}\right)\left(\frac{1}{2 \pi \sigma L_{r}+R_{r}}\right)\right|=1 \\
\frac{f_{c r}}{20}=\frac{K_{i}}{2 \pi K_{p}}
\end{array},\right.
$$

where $f_{c r}$ stands for the open-loop cross-over frequency of PI controller, $300 \mathrm{~Hz}$ here, $\sigma$ stands for the magnetic leakage factor of the doubly-fed generator, 0.043 here, $L_{r}$ stands for the rotor inductance of the doubly-fed generator, $1.7475 \mathrm{pu}$ here, and $R_{r}$ stands for the rotor resistance of the doubly-fed generator, $0.012 \mathrm{pu}$ here.

After the parameters of the doubly-fed generator were substituted, $K_{p}=0.35$ and $K_{i}=35$ were obtained.

\subsection{Experimental Operation}

The rotor speed was set as $1100 \mathrm{r} / \mathrm{min}$ (subsynchronous), and the output power was $9 \mathrm{~kW}$. Grid voltage $U_{\mathrm{ab}}$, stator current $I_{\mathrm{sa}}$, rotor current $I_{\mathrm{ra}}$ and output signal of $d$ axis of harmonic controller $U_{\text {rd }}$ when the proposed control method was used was measured using a power analyzer. Then the output signal of the traditional current control method was measured.

The rotor speed was set as $2000 \mathrm{r} / \mathrm{min}$ (hypersynchronous), and the output power was $22 \mathrm{~kW}$. Grid voltage $U_{\mathrm{ab}}$, stator current $I_{\mathrm{sa}}$, rotor current $I_{\mathrm{ra}}$ and output signal of $d$ axis of harmonic controller $U_{\text {rd }}$ when the proposed control method was used were measured using a power analyzer. Then the output signal of the traditional current control method was measured.

The rotor speed was set as $1100 \mathrm{r} / \mathrm{min}$ (subsynchronous), and the output power was $9 \mathrm{~kW}$. Grid voltage $U_{\mathrm{ab}}$, stator current $I_{\mathrm{sa}}$, rotor current $I_{\mathrm{ra}}$ and output signal of $d$ axis of harmonic controller $U_{\text {rd }}$ when the traditional current control method was used were measured using a power analyzer. Then the output signal of the traditional current control method was measured. Then the control strategy was turned into the control strategy, and the output signal was measured again.

\subsection{Experimental Results}

Case-1: Steady-state performance of the two methods under subsynchronous speed.

Fig. 5 shows four output signals of the traditional current control strategy under subsynchronous speed of rotor during grid connection. Fig. 6 shows four output signals of the method proposed in this study under subsynchronous speed of rotor during grid connection. The comparison of Fig. 5 and 6 suggested that the traditional current control strategy was difficult to inhibit harmonic current produced by harmonic voltage, and the stator current waveform was more stable under the control of the proposed control strategy, which indicated that the proposed control strategy had favourable suppression effect on harmonic current. 


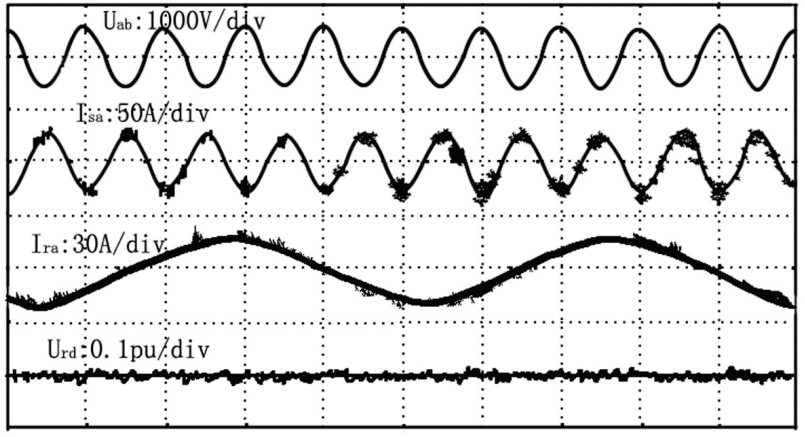

Figure 5 The steady-state performance of the traditional current control strategy under subsynchronous speed of rotor during grid connection

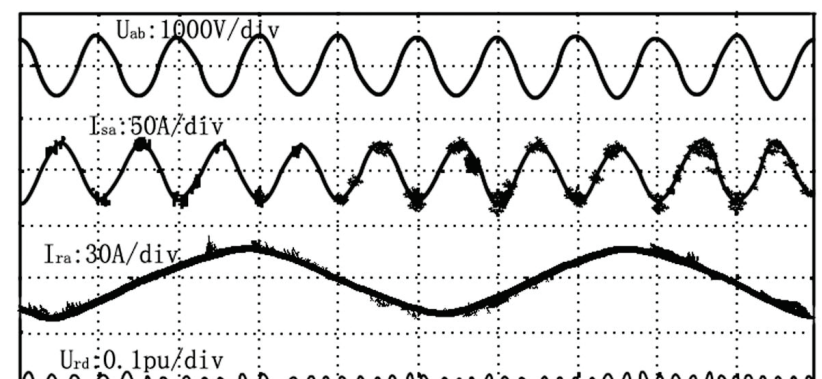
Urd :0.1pu/div

Figure 6 The steady-state performance of the resonant controller based control

strategy under subsynchronous speed of rotor during grid connection

Case-2: Steady-state performance of the two strategies under supersynchronous speed of rotor

Fig. 5 shows four output signals of the traditional current control strategy under supersynchronous speed of rotor during grid connection. Fig. 6 shows four output signals of the method proposed in this study under supersynchronous speed of rotor during grid connection.
The comparison of Fig. 7 and 8 suggested that the traditional current control stategy was difficult to inhibit harmonic current produced by harmonic voltage, and the stator current waveform was more stable under the control of the proposed control strategy, which indicated that the proposed control strategy had favourable suppression effect on harmonic current.

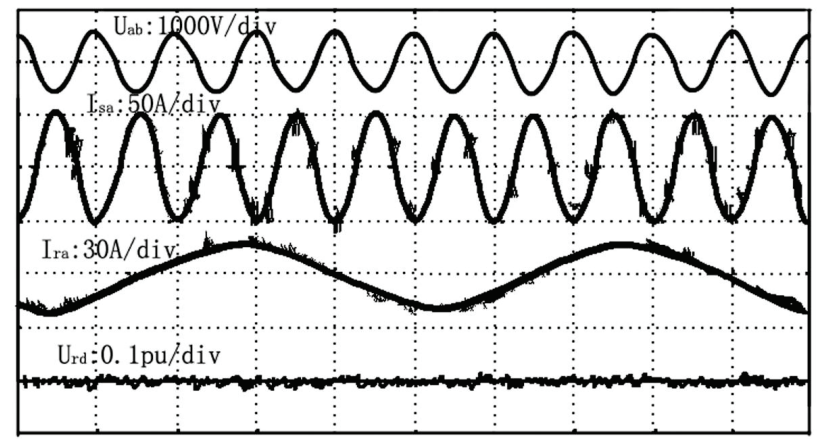

Figure 7 The steady-state performance of the traditional current control strategy under subsynchronous speed of rotor during grid connection

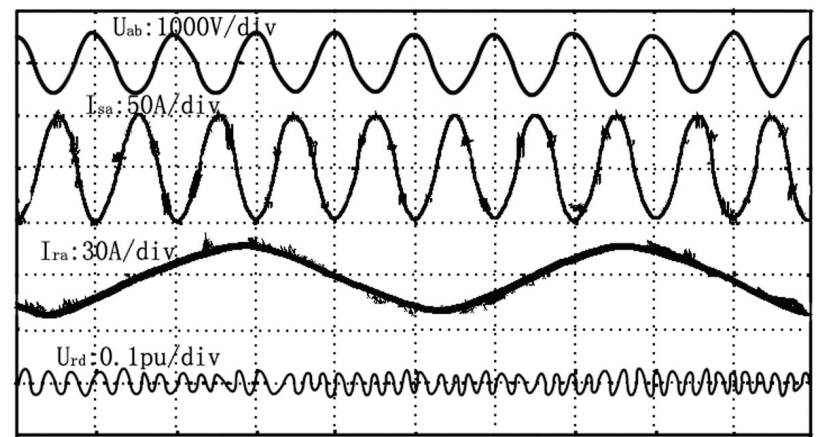

Figure 8 The steady-state performance of the resonant controller based control strategy under subsynchronous speed of rotor during grid connection

Table 2 The measured values of grid voltage and stator current harmonic under different rotor speeds

\begin{tabular}{|c|c|c|c|c|c|}
\hline \multirow[t]{2}{*}{ Rotor speed } & \multirow[t]{2}{*}{ Current } & \multicolumn{2}{|c|}{ The traditional current control strategy } & \multicolumn{2}{|c|}{$\begin{array}{l}\text { Resonant controller based stator current } \\
\text { harmonic control strategy }\end{array}$} \\
\hline & & Stator current & Grid voltage & Stator current & Grid voltage \\
\hline \multirow{3}{*}{$\begin{array}{l}\text { Subsynchronous speed } \\
\qquad(1100 \mathrm{r} / \mathrm{min})\end{array}$} & The $5^{\text {th }}$ harmonic current $/ \%$ & 3.9 & 1.5 & 0.8 & 1.5 \\
\hline & The $7^{\text {th }}$ harmonic current $/ \%$ & 4.4 & 0.6 & 1.1 & 0.6 \\
\hline & Static current change $/ \%$ & 6.3 & 1.9 & 2.5 & 1.9 \\
\hline \multirow{3}{*}{$\begin{array}{l}\text { Supersynchronous speed } \\
\qquad(2000 \mathrm{r} / \mathrm{min})\end{array}$} & The $5^{\text {th }}$ harmonic current $/ \%$ & 13.5 & 1.5 & 2.5 & 1.5 \\
\hline & The $7^{\text {th }}$ harmonic current $/ \%$ & 3.5 & 0.6 & 1.1 & 0.6 \\
\hline & Static current change $/ \%$ & 14.1 & 1.9 & 5.1 & 1.9 \\
\hline
\end{tabular}

As shown in Tab. 2, the $5^{\text {th }}$ and $7^{\text {th }}$ harmonic stator current were $13.5 \%$ and $3.5 \%$ respectively under subsynchronous speed when the traditional control strategy was used and decreased to $2.5 \%$ and $1.1 \%$ when the stator harmonic current control strategy was used; the stator current decreased from $14.1 \%$ to $5.1 \%$; moreover the $5^{\text {th }}$ and $7^{\text {th }}$ harmonic voltage of grid was $1.5 \%$ and $0.6 \%$ respectively, indicating no changes. Under supersynchronous speed, the $5^{\text {th }}$ and $7^{\text {th }}$ harmonic stator current were $3.9 \%$ and $4.4 \%$ respectively and decreased to $0.8 \%$ and $1.1 \%$ respectively when the stator harmonic current control strategy was used, the stator current decreased from $6.3 \%$ to $2.5 \%$ respectively, and the $5^{\text {th }}$ and $7^{\text {th }}$ harmonic voltage of grid were $1.5 \%$ and $0.6 \%$ respectively, indicating no changes.

Case-3: Transient response under supersynchronous speed when the traditional current control strategy is switched to the stator current harmonic control strategy

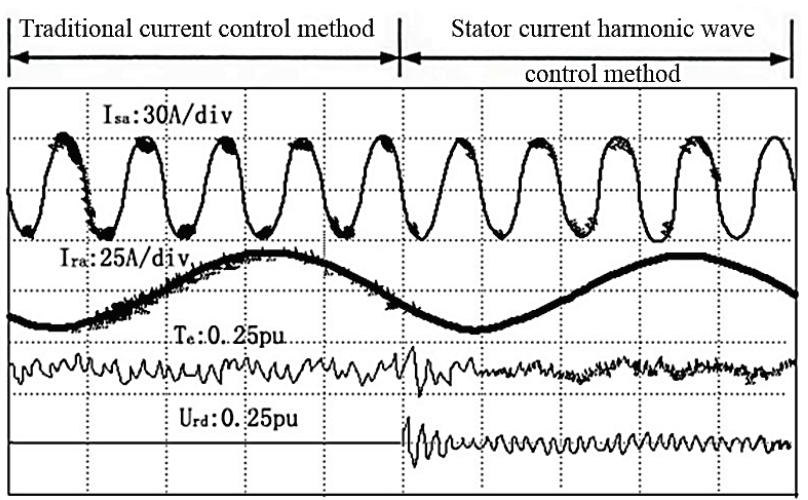

Figure 9 The transient response under under supersynchronous speed when the traditional current control strategy is switched to the stator current harmonic control strategy

The transient response of doubly-fed motor when the traditional current control strategy was switched to the 
stator current harmonic control strategy is shown in Fig. 9. The transition time for transition was $20 \mathrm{~ms}$. Four signal curves in the figure were stator current, rotor current, electromagnetic torque and output of $\mathrm{d}$ axis of harmonic controller. It could be seen from the figure that $6^{\text {th }}$ pulse of the electromagnetic torque was significantly inhibited after switching, indicating that the control method could effectively inhibit the influence of grid harmonic voltage on electromagnetic torque.

\section{CONCLUSION}

In this study, harmonic current suppression experiment was carried out on the double-fed wind power gridconnected experimental platform built based on the mathematical model of wind power system using the stator current harmonic control method, and moreover the control strategy was compared with the traditional current control strategy. The results are as follows. When the rotor was subsynchronous and the stator output power is $9 \mathrm{~kW}$, the $5^{\text {th }}$ and $7^{\text {th }}$ harmonic currents decreased $11 \%$ and $2.4 \%$ respectively under the stator current harmonic control, the stator current decreased $9 \%$, and the grid harmonic voltages were unchanged $(1.5 \%$ and $0.6 \%)$. When the rotor was supersynchronous and the stator output power was 22 $\mathrm{kW}$, the $5^{\text {th }}$ and $7^{\text {th }}$ harmonic currents decreased $3.1 \%$ and $3.3 \%$ respectively under the stator current harmonic controller, the stator current decreased $3.8 \%$, and the grid harmonic voltage was unchanged $(1.5 \%$ and $0.6 \%)$. When the rotor was supersynchronous, the stator output power was $22 \mathrm{~kW}$, and the grid-connected control strategy was switched from the traditional current control method to the stator current harmonic control method, the $6^{\text {th }}$ pulse of electromagnetic torque was significantly suppressed.

\section{Acknowledgement}

We completed this paper based on the project of Study on the key technology of electric vehicle charging facilities for the energy internet supported by Nanchong bureau of science \&technology and intellectual property.

\section{REFERENCES}

[1] Wang, L., Xie, X., Jiang, Q., \& Liu, X. (2015). Centralised solution for subsynchronous control interaction of doubly fed induction generators using voltage-sourced converter. Generation Transmission \& Distribution Iet, 9(16), 27512759. https://doi.org/10.1049/iet-gtd.2015.0720

[2] Su, J., Shi, L., Yao, L., Ni, Y., \& Guo, Z. (2015). A Comparative Sub-synchronous Resonance Analysis of Gridconnected Doubly Fed Induction Generator Based and Permanent Magnet Synchronous Generator Based Wind Farms. Electric Machines \& Power Systems, 43(7), 792-809. https://doi.org/10.1080/15325008.2014.1002588

[3] Li, Q., Cheng, P., Hao, X., \& Zhang, J. (2017). Stator current vector control strategy of doubly fed induction generator using proportional-resonant regulators. The Journal of Engineering, 2017(13), pp. 1728. https://doi.org/10.1049/joe.2017.0627

[4] Yu, Q. \& Heng, N. (2015). Resonant-based Sliding Mode Control of Doubly-fed Induction Generators under Unbalanced and Harmonic Grid Voltages. Proceedings of the CSEE, 35(2), 465-476.
[5] Ratna, A., Pachauri, R. K., \& Chauhan, Y. K. (2017). Mitigation of sub-synchronous resonance in doubly fed induction generator based wind energy system. IEEE International Conference on Power Electronics, Intelligent Control and Energy Systems / Delhi, 1-5. https://doi.org/10.1109/ICPEICES.2016.7853451

[6] Ji, K. \& Huang, S. (2018). Direct Flux Control for StandAlone Operation Brushless Doubly Fed Induction Generators Using a Resonant-Based Sliding-Mode Control Approach. Energies, 11(4), pp. 814. https://doi.org/10.20944/preprints201802.0058.v1

[7] Xu, H., Wei, S., Liao, Z., \& Ma, X. (2016). Dynamic modeling and resonant control of doubly fed induction generators during generalized grid voltage distortions. Power Electronics and Motion Control Conference / Hefei, 3526-3530.

[8] Cheng, M., Jiang, Y., Han, P., \& Wang, Q. (2017). Unbalanced and Low-Order Harmonic Voltage Mitigation of Stand-Alone Dual-Stator Brushless Doubly Fed Induction Wind Generator. IEEE Transactions on Industrial Electronics, PP, 99, 9135-9146. https://doi.org/10.1109/TIE.2017.2779422

[9] Ai, H., Bai, J., \& Xie, G. (2017). Research on power decoupling control strategy for Doubly-Fed wind turbine generator. $36^{\text {th }}$ Chinese Control Conference (CCC) / Dalian, 5004-5008. https://doi.org/10.23919/ChiCC.2017.8028146

[10] Mohammadpour, H. \& Santi, E. (2015). Analysis of Subsynchronous Resonance (SSR) in Doubly-fed Induction Generator (DFIG)-Based Wind Farms. Morgan \& Claypool, pp. 64. https://doi.org/10.2200/S00660ED1V01Y201508PEL009

[11] Mendes, V. F., Pereira, H., Matos, F. F., Hofmann, W., \& Silva, S. R. (2016). Doubly-fed induction generator control during unbalanced grid conditions. Power Electronics Conference and, Southern Power Electronics Conference / Fortaleza, 1-6. https://doi.org/10.1109/COBEP.2015.7420211

[12] Bayhan, S. \& Abu-Rub, H. (2015). Model predictive sensorless control of standalone doubly fed induction generator. ECON 2014 - $40^{\text {th }}$ Annual Conference of the IEEE Industrial Electronics Society / Dallas, 2166-2172. https://doi.org/10.1109/IECON.2014.7048802

[13] Ghosh, S., Kamalasadan, S., Senroy, N., \& Enslin, J. (2016). Doubly Fed Induction Generator (DFIG)-Based Wind Farm Control Framework for Primary Frequency and Inertial Response Application. IEEE Transactions on Power Systems, 31(3), 1861-1871. https://doi.org/10.1109/TPWRS.2015.2438861

[14] Nian, H. \& Song, Y. P. (2015). Multiple target implementation for a doubly fed induction generator based on direct power control under unbalanced and distorted grid voltage. Frontiers of Information Technology \& Electronic Engineering, 16(4), 321-334. https://doi.org/10.1631/FITEE.1400170

[15] Huang, Q., Zou, X., Zhu, D., \& Kang, Y. (2016). Scaled Current Tracking Control for Doubly Fed Induction Generator to Ride-Through Serious Grid Faults. IEEE Transactions on Power Electronics, 31(3), 2150-2165. https://doi.org/10.1109/TPEL.2015.2429153

[16] Coteli, R., Acikgoz, H., Ucar, F., \& Dandil, B. (2017). Design and implementation of Type-2 fuzzy neural system controller for PWM rectifiers. International Journal of Hydrogen Energy, 42(32), 20759-20771. https://doi.org/10.1016/j.jihydene.2017.07.032 


\section{Contact information:}

\section{Jin XU}

Corresponding author

School of Electrical Engineering and Information,

Southwest Petroleum University,

No. 8, Xindu Road, Chengdu 610500, China

jinxuxn@yeah.net

\section{Haiyun CHEN}

School of Electrical Engineering and Information,

Southwest Petroleum University,

No. 8, Xindu Road, Chengdu 610500, China

\section{Wanming Z $\mathrm{HAO}$}

School of Electrical Engineering and Information,

Southwest Petroleum University,

No. 8, Xindu Road, Chengdu 610500, China

\section{Qian LI}

School of Electrical Engineering and Information

Southwest Petroleum University,

No. 8, Xindu Road, Chengdu 610500, China 